\title{
Educação ambiental: diálogo de saberes populares sobre ervas medicinais na comunidade quilombola Areal da Baronesa - Porto Alegre, RS
}

\begin{abstract}
Resumo
Este artigo, de abordagem qualitativa, tem como objetivo refletir a respeito do diálogo de saberes populares sobre ervas medicinais, instrumentalizado pela ação de Educação Ambiental junto a um grupo de mulheres quilombolas na cidade de Porto Alegre (RS), na busca da valorização de seus conhecimentos tradicionais. As análises partem dos registros sistematizados em relatórios semanais das oficinas de ervas medicinais e das oficinas de sabonetes de ervas, realizados no período de setembro a novembro de 2017.Como suporte para as compreensões dos resultados, tem-se como referencial teórico o diálogo de saberes desenvolvido por Leff (2009); a abordagem crítica e transformadora da EA elaborada por Layrargues (2012); e a EA popular emancipatória de Sorrentino (2014) e Tassara; Tassara; Ardans (2014).
\end{abstract}

Palavras-chave: Educação Ambiental. Quilombolas - Mulheres. Ervas - Uso Terapêutico.

\section{Salete Vedovatto Facco}

Mestranda em Educação pela

Universidade Federal do Rio

Grande do Sul - UFRGS.

Brasil

sementesdomundo@hotmail.com

\section{Vanessa Caporlíngua}

Doutora em Educação Ambiental pela Universidade Federal de Rio

Grande - FURG.

Professora da Universidade

Federal do Rio Grande - FURG. Brasil

vcaporlingua@gmail.com

\section{Vanessa dos Santos Moura}

Doutora em Educação Ambiental pela Universidade Federal de Rio

Grande - FURG.

Brasil

vanessamoura@furg.br

\section{Para citar este artigo:}

FACCO, Salete Vedovatto; CAPORLÍNGUA, Vanessa; MOURA, Vanessa dos Santos. Educação ambiental: diálogo de saberes populares sobre ervas medicinais na comunidade quilombola Areal da Baronesa - Porto Alegre, RS. Revista PerCursos, Florianópolis, v. 19, n.41, p. 179 - 202, set./dez. 2018.

\section{DOI: $10.5965 / 1984724619412018179$}

http://dx.doi.org/10.5965/1984724619412018179 


\title{
Environmental education: dialogue of popular knowledge on medicinal herbs with a kilombola community (Porto Alegre)
}

\begin{abstract}
This article, in a qualitative approach, aims to reflect on the dialogue of popular knowledge about medicinal herbs, using as a tool the Environmental Education (EE) action with a group of women from a Quilombo in Porto Alegre (RS). We search for valorization of their traditional knowledge. The analysis starts from the systematized records in weekly reports of herbs and herbal soap workshops, carried out from September to November 2017. As support for the analyzes, the theoretical framework is the dialogue of knowledge developed by Leff (2009); the critical and transformative approach of EE developed by Layrargues (2012); and the popular emancipatory EE of Sorrentino (2014) and Tassara; Tassara; Ardans (2014).

Keywords: Environmental Education. Kilombola Women. Herbs - Therapeutic use.
\end{abstract}




\section{Introdução}

Este artigo tem a finalidade de apresentar resultados de um projeto de Ação de Educação Ambiental (EA) realizado entre setembro e novembro de 2017, vinculado à PósGraduação em Educação Ambiental, pela Universidade Federal do Rio Grande - FURG. Essa ação de EA teve como objetivo instrumentalizar o diálogo de saberes populares sobre ervas medicinais e estimular a possível autovalorização sobre esses saberes, como parte importante na consolidação da vida social de uma comunidade quilombola, localizada no município de Porto Alegre no estado do Rio Grande do Sul (RS).

Este projeto se apoia na Educação Ambiental de perspectiva crítica e transformadora, entendendo que a sociedade é composta por múltiplos grupos sociais com diferentes visões de mundo, experiências e tradições.

Do ponto de vista global, não se pode negar que os conhecimentos são padronizados e passam por processos de massificação, sob forte influência dos recursos midiáticos vigentes e das atuais tecnologias de informação e comunicação. A sociedade assimila os conhecimentos sob o filtro, muitas vezes, de interesses econômicos e financeiros, negando ou subjugando os conhecimentos populares em favor de seu benefício econômico. Essa massificação do conhecimento, na contemporaneidade, tende a se sobrepor aos conhecimentos localmente produzidos, de cunho popular e cotidiano. Através desse projeto, propôs-se enfatizar a valorização desses saberes populares sobre ervas medicinais. O projeto foi realizado na sede de Associação Quilombola e a opção em trabalhar especificamente com mulheres se deveu ao seu aparente papel de dominância em relação ao grupo, seja na tomada de decisões, seja no controle dos espaços domésticos e comunitários, ou ainda, na transmissão dos conhecimentos através de gerações.

O artigo está dividido em três partes. Primeiramente, será apresentado e discutido o referencial teórico, dando ênfase ao diálogo de saberes (LEFF, 2009), práxis educativas da EA (LAYRARGUES, 2012), EA Popular nos processos emancipatórios (SORRENTINO, 2014; e TASSARA; TASSARA; ARDANS, 2014). A segunda parte apresenta a pesquisa realizada com base nos documentos gerados a partir dos relatórios reflexivos da ação de 
EA, como pesquisa participante, durante as oficinas de ervas e de sabonetes, com suporte teórico de Figueiredo (2007). Na terceira, são apresentadas reflexões a partir da análise dos relatórios de campo e materiais empíricos.

\section{Percursos teóricos da pesquisa}

As práxis educativas são categorizadas por Layrargues (2012, p. 403), em três macrotendências de EA: a conservacionista, a pragmática e a crítica. A conservacionista reproduz ações educativas reducionistas e fragmentadas; mostra a dominação da natureza pelo ser humano e aceita a sua mercantilização.

Já a macrotendência pragmática abrange as correntes da Educação para o Desenvolvimento Sustentável e para o Consumo Sustentável, apoiada nas tecnologias limpas, nos sistemas de gestão ambiental, na criação de mercados verdes, serviços ecossistêmicos de racionalização do padrão de consumo, e na criação de indicadores de sustentabilidade.

Por sua vez, a macrotendência crítica, cujas propostas foram utilizadas para pensar epistemologicamente as ações de EA realizadas, apresenta uma abordagem pedagógica da Educação Ambiental Popular, contextualizadora e problematizadora. Tal abordagem crítica, mais próxima aos interesses dessa pesquisa, propõe desvelar a realidade com o fito de contribuir com a transformação da sociedade atual, trabalhando na realidade cotidiana e visando à superação das relações de dominação e de exclusão, que caracterizam a sociedade contemporânea.

O que diferencia a EA crítica e transformadora, das demais perspectivas teóricas de EA é o fato de esta ser a única que busca pensar a complexidade ambiental a partir de sua perspectiva política pedagógica. AEA crítica propõe-se estudar novas bases de relações sociedade-natureza, buscando por meio da práxis educativa, a ampliação da consciência humana para um melhor enfrentamento das crises atuais. 


\section{O saber ambiental: uma nova forma de pensar, conhecer e atuar no mundo}

Os saberes populares e a valorização do meio natural, transmitidos entre gerações e culturas por meio do diálogo, precisam ser reafirmados, pois são essenciais para a sustentabilidade da vida (e da humanidade). Conforme Leff (2009, p. 19) “o saber social emerge de um diálogo de saberes, do encontro de seres diferenciados pela diversidade cultural, orientando o conhecimento para a formação de uma sustentabilidade partilhada". O referido autor retoma a relevância dos saberes populares e das coisas simples que têm sido ignoradas ou subjugadas em nome do que se considera ciência, mas que são importantes para alguns grupos sociais e que aproximam os sujeitos do entendimento da sua ancestralidade, do seu contexto e de sua realidade. Nesse sentido:

O saber ambiental busca conhecer o que as ciências ignoram, porque seus campos de conhecimento projetam sobras sobre o real e avançam, disciplinando paradigmas e subjugando. (...) O ambiente é um saber sobre a natureza externalizada, sobre as identidades desterritorializadas, a respeito do real negado e dos saberes subjugados (...) (LEFF, 2009, p. 18-19)

Alguns dos conhecimentos necessários para a vivência em sociedade não são descobertas recentes para a humanidade. O uso de ervas para o tratamento de doenças remonta a tempos longínquos de, aproximadamente, 2000 anos atrás: os gregos e os romanos, por exemplo, usavam a babosa (Aloe Vera) como cicatrizante e, por séculos, ela tem sido usada para curar queimaduras, inflamações e feridas da pele. Esse saber, assim como tantos outros, foi repassado entre as gerações e permanecem necessários e aplicados até os dias de hoje. No caso da babosa, a ciência moderna reconhece suas propriedades medicinais e, inclusive, pode-se encontrá-la em forma de medicamentos produzidos por laboratórios na indústria farmacêutica (GRANDI, 2014, p. 168).

O mundo moderno, dotado de novas e avançadas tecnologias no âmbito farmacêutico, por décadas subjugou o conhecimento e o uso de saberes populares sobre ervas medicinais, presentes em territórios muitas vezes desconsiderados pela academia. Com isso, os sujeitos que participam desses territórios também podem ter subestimado e 
desvalorizado o conhecimento que tinham sobre determinados assuntos, dificultando sua capacidade de empoderamento ${ }^{1}$ (poder fazer) diante desses saberes.

\section{A EA Popular nos processos emancipatórios}

Outro conceito empregado como suporte teórico para essa ação é o de Educação Ambiental Popular (EAP), entendido enquanto um fundamento para as práticas educativas, com vistas a melhorar a qualidade de vida nas comunidades. Segundo Reigota (1992), a EAP tem o objetivo de promover a consciência crítica e uma sensibilidade acerca do meio ambiente e dos problemas a ele associados. Ela inclui a necessidade de ações que visem ao potencial crítico dos grupos populares e, com isso, impulsionar a tomada de decisões acerca dos problemas que os afligem cotidianamente em suas comunidades.

Nesse sentido, Sorrentino (2014, p. 146-147) afirma que é urgente que os projetos educativos (como a ação aqui referida) cheguem até as comunidades e grupos sociais para, junto deles e com eles, estimular a capacidade reflexiva e a criatividade desses grupos. Também, esses projetos devem incentivar a vontade e a capacidade de imaginar e devem enunciar o seu projeto de futuro, dialogando sobre ele, empoderando-se e ampliando o desejo de se emancipar. Nesse sentido, o Educador Ambiental Popular deve saber que o seu papel é de propiciar um diálogo empoderador, crítico e, também, acolhedor, que permita provocar sentimentos, enriquecer a alma e provocar os sonhos (SORRENTINO, 2014, p.150).

Segundo Tassara; Tassara; Ardans (2014), a EA popular crítica objetiva, entre outras coisas, a prática educativa emancipadora, no entendimento de que é nas ações do campo ambiental com participação dos envolvidos, indivíduos ou comunidade, que se pretende suscitar reflexões e práticas libertárias e emancipatórias, valorizando saberes populares e suas vivências.

\footnotetext{
${ }^{1}$ Segundo Horochovski e Meirelles (2007, p. 486), empoderamento se trata da "constituição deorganizações e comunidades responsáveis, mediante um processo no qual os indivíduos queas compõem obtêm controle sobre suas vidas e participam democraticamente no cotidiano dediferentes arranjos coletivos e compreendem criticamente seu ambiente".
} 
No entanto, a participação de todos os envolvidos, como agentes de todo o processo, é que pode se caracterizar como emancipatória, pois promove autonomia de decisão, que significa emancipação, e, consequentemente, pode ser entendida como "ser ou fazer parte" (TASSARA; TASSARA; ARDANS, 2014, p. 158). Assim, o educando participante se empodera, se emancipa.

\section{Metodologia}

Este projeto de ação tem cunho qualitativo e adota a metodologia da Pesquisa Participante, de acordo com os pressupostos teóricos e metodológicos de Brandão (1984; 2003). A característica principal da Pesquisa Participante é a participação e a inserção tanto do pesquisador como dos sujeitos pesquisados no estudo. Brandão afirma que os "pesquisadores e pesquisados são sujeitos de um mesmo trabalho comum, ainda que com situações e tarefas diferentes" (1984, p.10).

Tendo como foco a ressignificação e o resgate dos saberes populares sobre ervas medicinais, optou-se pela realização de oficinas de sabonetes de ervas medicinais e oficinas de chás, procurando consolidar na comunidade um espaço de diálogo e valorização dos saberes populares. O projeto, ao propor essas oficinas, criou um espaço de diálogo de saberes, no qual pesquisou, na forma de conversas, para compreender: Qual o entendimento das mulheres sobre as ervas? Que uso das ervas fazem no seu cotidiano? No encontro do conhecimento trazido pela pesquisa com o conhecimento popular das mulheres sobre as ervas, suas memórias e experiências vividas, procurou-se perceber a importância desse conhecimento na valorização da sua própria história.

Para a sistematização da ação proposta pelo projeto de EA, foram elaborados diferentes materiais impressos para auxiliar na didática das oficinas. Para tal, preparou-se a seguinte sequência de procedimentos: 1) Passo-a-passo para a produção de sabonetes artesanais: nesse material são impressos os aspectos relevantes sobre os métodos utilizados para a produção de sabonetes de ervas medicinais; 2)Lista de ervas medicinais 
com informações sobre seu uso tópico; 3) Oficina dos chás; 4)Relógio do corpo humano²: texto explicativo sobre o relógio biológico do corpo humano.

Nesta pesquisa adotaram-se os pressupostos teóricos e metodológicos com suporte na proposta de Figueiredo (2007), em sua abordagem sobre a pesquisa documental como objeto de investigação, tais como os relatórios produzidos. Tais documentos são, portanto, "quaisquer materiais escritos que possam ser usados como fonte de informação sobre o comportamento humano" (PHILLIPS, 1974 apud LÜDKE; ANDRÉ, 1986, p. 187). Caracterizam-se por trazer em seu conteúdo informações e esclarecimentos sobre determinadas questões e servem de prova para outras, de acordo com o interesse do pesquisador durante sua análise.

Como forma de registro, foram feitos relatórios dos encontros, com anotações em diário de campo, em que foram colocadas informações consideradas relevantes, os dizeres considerados mais significativos $e$ as questões entendidas como problematizadoras, em conversas aparentemente despretensiosas. Além disso, foram feitos registros fotográficos, editados e organizados de forma a compor o material empírico da pesquisa que sofreu a análise. Por fim, como sugere Lüdke e André (1986), voltou-se a examinar os dados que compõem o corpus desta análise, no intuito de aumentar o conhecimento, identificando os elementos emergentes que precisam ser mais aprofundados.

\section{Contextualização da experiência e formação do grupo}

A temática apresentada neste projeto de pesquisa é a EA enquanto instrumento de sensibilização sobre os saberes populares pertinentes a comunidades quilombolas,

\footnotetext{
${ }^{2}$ RELÓGIO DO CORPO HUMANO NO RIO GRANDE DO SUL: "O Horto Medicinal: Relógio do Corpo Humano é uma metodologia desenvolvida pela EMATER/RS. Há um fator inovador, a união das plantas medicinais com os principais órgãos do corpo humano, informando os horários de maior atividade de cada órgão e quais as plantas recomendadas para tratamento de doenças específicas.

(http://www.biodiversidade.rs.gov.br/arquivos/1159290630estudo_caso_HORTO_MEDICINAL_RELOGIO_ DO_CORPO_HUMANO.pdf).
} 
mais especificamente de mulheres quilombolas, tendo como estudo de caso o Quilombo 3 Areal da Baronesa, em Porto Alegre (RS).

Destaca-se a experiência dessa comunidade de luta e resistência às forças do capital imobiliário, pois, apesar de se tratar de um lote pequeno em uma área de aproximadamente 4,5 mil $\mathrm{m}^{2}$, localiza-se em um perímetro urbano suscetível à especulação imobiliária. Situada no limite entre os bairros Cidade Baixa e Menino Deus, na Rua Luiz Guaranha, o Quilombo Areal da Baronesa comporta aproximadamente oitenta famílias, tendo sua origem no século XIX, quando passou a agregar ex-escravos e seus

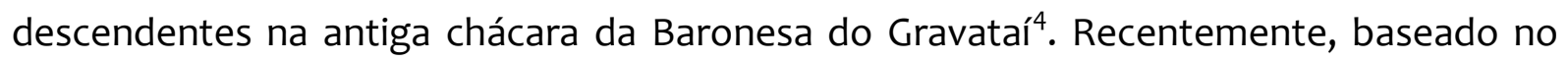
Decreto Federal 4887/2003, que regulamenta o reconhecimento, delimitação, demarcação e titulação das terras ocupadas por remanescentes das comunidades dos quilombos, em julho de 2015, o Município de Porto Alegre reconheceu e doou o espaço físico ocupado à Associação Quilombola do Areal da Baronesa.

A Associação Quilombola é um espaço que proporciona várias vivências, por vezes entre os próprios membros do grupo, porque é ali o espaço das reuniões, das festas; outras vezes entre os membros do grupo e os visitantes ou pesquisadores, que também usam esse espaço para as ações de pesquisa. À luz do pensamento de Paulo Freire, que diz "quem ensina aprende ao ensinar e quem aprende ensina ao aprender" (1988, p.25), esse espaço constitui um lugar de ensino e de aprendizagens e, por isso, se propôs uma ação de EA que buscou valorizar os saberes populares dessas mulheres, suas memórias e vivências e entender sua relação com a natureza.

A ação ocorreu na sede de Associação Quilombola e a opção em trabalhar especificamente com mulheres se deveu ao seu aparente papel de dominância em

\footnotetext{
${ }^{3}$ O termo quilombo, segundo O'Dwyer (2005, p. 17-18), passa por um processo de ressemantização com fim de designar os segmentos negros encontrados em diferentes regiões e contextos do Brasil. Para esse autor, "contemporaneamente, portanto, o termo quilombo não se refere a resíduos ou resquícios arqueológicos de ocupação temporal ou de comprovação biológica".

${ }^{4}$ O Areal da Baronesa sempre foi reconhecido como um dos principais redutos negros de Porto Alegre (RS). Reconhecido também pela música popular e pela religião, o local abrigava a chácara da Baronesa do Gravataí. Com a morte da baronesa e a abolição da escravatura, o Areal foi ocupado por negros alforriados da senzala da chácara que passaram a trabalhar nos solares da região.
} 
relação ao grupo, seja na tomada de decisões, seja no controle dos espaços domésticos e comunitários, ou ainda, na transmissão dos conhecimentos através de gerações.

É importante estabelecer a diferença entre saberes popular e tradicional. Existem diferentes definições e considerações sobre os saberes populares. Para Pinheiro e Giordan (2010), o saber popular é um conjunto de conhecimentos que são adquiridos de forma empírica, a partir do fazer, e são transmitidos de geração em geração, por meio oral, gestos, atitudes, baseados em crenças, opiniões, superstições. Esses saberes são produzidos por grupos específicos (familiar ou comunidade). Para Dickmann e Dickmann (2008, p. 70) “o saber popular é entendido como aquele que é fruto das várias experiências vividas e convividas em tempos e espaços diversos na história do povo".

Dos conceitos descritos acima, a valorização dos conhecimentos tradicionais e populares de um determinado grupo é muito relevante, pois os conhecimentos populares fortalecem as tradições, ou seja, quanto mais a comunidade reconhece sua cultura no cotidiano, mais fortalece os saberes tradicionais (as crenças, os rituais, as comidas, a dança). Os saberes populares reforçam os saberes tradicionais e ambos proporcionam o fortalecimento desses conhecimentos e do reconhecimento da própria história.

\section{Contexto do grupo e a prática}

Nas duas primeiras semanas de outubro, a ação foi levada a efeito com o objetivo de criar espaços de diálogos e de saberes, para ativar memórias de saberes populares, ainda significativos e valorosos para a comunidade quilombola. O grupo formado para as atividades foi composto por oito mulheres da comunidade, com idades que variavam entre 27 e71 anos e a neta de uma delas, com 13 anos 5 . Todas apresentam uma vida mais centrada no próprio quilombo e as que já trabalharam de alguma maneira fora do espaço quilombola, agora estão aposentadas. Todas são de baixa escolaridade e há duas senhoras analfabetas funcionais (Dona E. e Dona L.). Todas receberam material didático com dois conteúdos básicos: o primeiro, continha o passo-a-passo da produção de

\footnotetext{
${ }^{5}$ Todas as mulheres participantes da pesquisa assinaram Termo de Consentimento Livre e Esclarecido no que se refere ao uso de suas falas e da sua imagem.
} 
sabonete de ervas; e o segundo discorria sobre o uso das ervas como chás. Esses materiais tiveram o papel de levar uma informação científica trazida pela pesquisa e também um papel facilitador de troca de informações sobre ervas medicinais. As mudas de ervas com as quais trabalhamos foram levadas pela pesquisadora e plantadas em jardim suspenso na própria Associação, uma vez que o Quilombo não possui espaço físico para plantio de ervas.

O fato de perceber que existe dificuldade das mulheres em interagir com 0 material didático elaborado para as oficinas, especialmente as analfabetas funcionais, trouxe à tona a necessidade de se repensar as atividades propostas, e elaborar algumas dinâmicas de ação para que as mulheres pudessem participar mais facilmente e interagir de forma mais lúdica. Chamou-se a primeira atividade de "Cuidado com a Plantinha", que implicou em cuidados com uma muda de erva de livre escolha, em que cada uma levou para casa sob seus cuidados até a próxima oficina. A cada semana uma dessas mudas seria escolhida para ser estudada e ficaria sobre a mesa. As demais eram colocadas num espaço criado na parede onde ficavam expostas durante as oficinas (Figura 1). Essa atividade estabeleceu um vínculo com a erva escolhida, e permitiu a reflexão e o resgate nas memórias do conhecimento; depois, de forma lúdica, dialogou-se coletivamente nas oficinas.

Figura 1 - Atividade "Cuidado com a Plantinha"

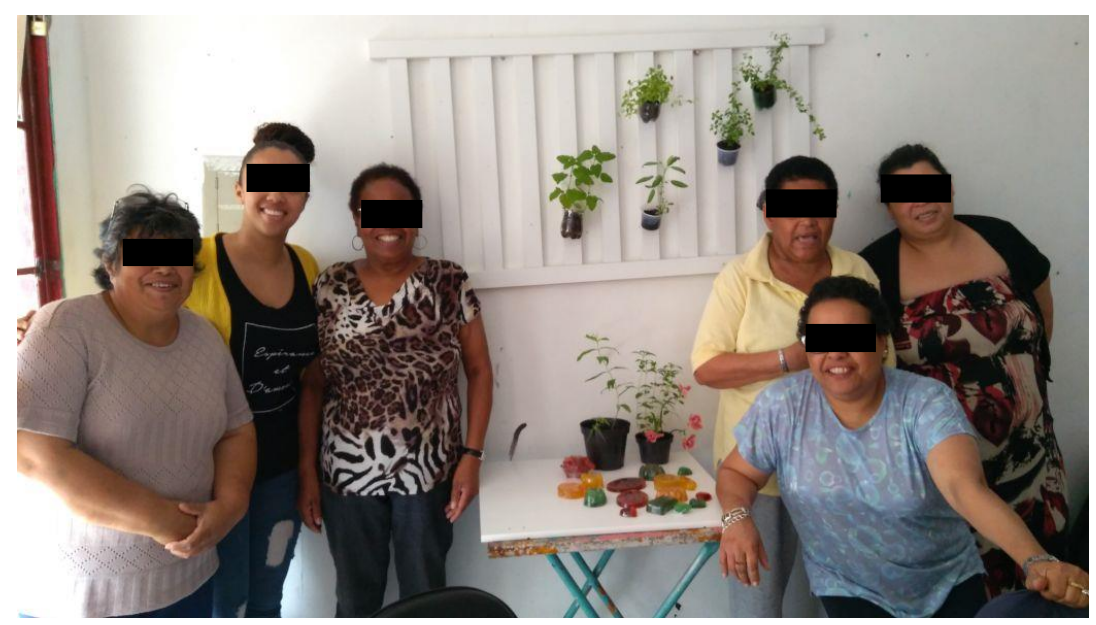

Fonte: Arquivo pessoal, 2017 
Essa estratégia permitiu que se superasse a dificuldade encontrada por algumas delas com o material didático, e permitiu que se expressassem de forma falada sobre seus sentimentos e conhecimentos sobre as ervas. Contudo, nem todas conseguiram manter seus cuidados com a plantinha, e quase metade não levou as mudas, que eram esquecidas em suas casas; mas, a outra metade que as trouxe, assegurou o desenvolvimento da atividade.

\section{Oficina de ervas: valorizando saberes populares}

Entrou-se na terceira e quarta semanas de outubro com maior foco na valorização dos saberes sobre ervas e na importância desse saber para a cultura atual e das futuras gerações, como um dos objetivos específicos da ação de EA proposta; e para dar continuidade na busca por essa valorização, fez-se, na sequência, a atividade dos cuidados com a plantinha.

Para melhor interagir com as mulheres, organizou-se uma dinâmica dos saberes (você sabia?), que consiste em colocar uma muda sobre a mesa e junto um cartaz com uma informação da historicidade da erva em questão; começou-se pela arruda. Essa dinâmica revelou, na forma de diálogo,o que elas sabem e o que querem dizer sobre as ervas e, o mais importante, mostra na forma de registro escrito os conhecimentos sobre as ervas que essas mulheres têm, e que são usados por elas e pela comunidade nos dias atuais. No cartaz dizia: Você sabia que a arruda era usada como anti-afrodisíaco para os homens e estimulante para as mulheres? As mulheres, por sua vez, tinham para relatar ou escrever nas folhinhas de papel o que sabiam sobre essa erva; cada uma lia o que escreveu e colocava a sua informação sobre a mesa junto à plantinha; as que não escrevem, o fizeram de forma falada (Figuras 2 e 3 ).

Essa atividade ocorreu até que se passasse por todas as dez mudas de ervas sobre a mesa. A dinâmica permitiu a obtenção do registro dos saberes dessas mulheres (material empírico) e a interpretação das falas significativas através dos relatos feitos. 
Figuras 2 e 3 - Dinâmica dos saberes: Você sabia?
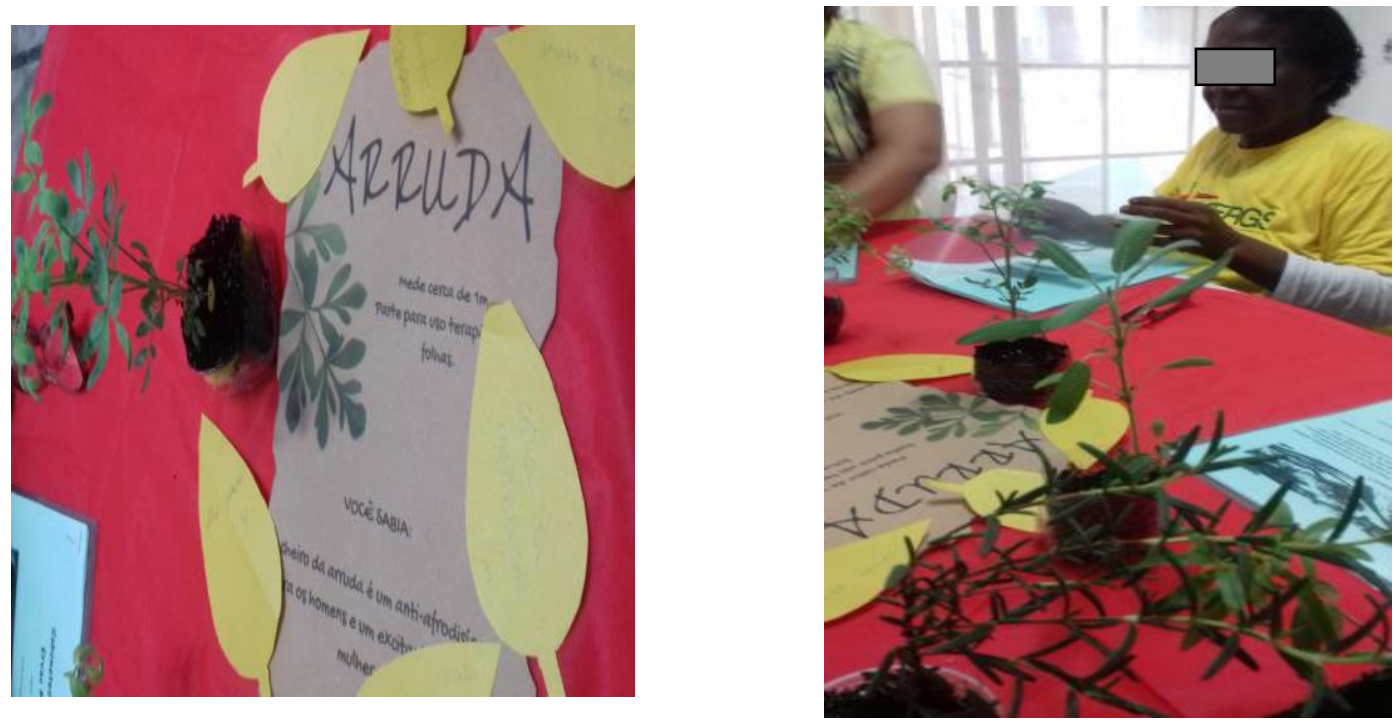

Fonte: Arquivo pessoal, 2017

Foram muitas as falas significativas: as mulheres se mostraram saudosas de situações que remetiam aos entes mais antigos, mas no final todas já conheciam ou já haviam feito o uso da arruda em determinado momento de suas vidas, "quer para o bem ou para o mal", segundo suas próprias palavras. Seus relatos corroboram as afirmações de Leff (2009, p.18), para quem o saber ambiental "reafirma o ser no tempo e o conhecer na história; estabelece-se em novas identidades e territórios de vida; reconhece o poder do saber e da vontade de poder como um querer saber".

Dentre muitos relatos, uma mulher mencionou usar a arruda para afastar mau olhado; outras ouviram falar que os mais antigos usavam para aliviar a dor de cabeça, usando um ramo atrás da orelha. Embora elas não soubessem o porquê desta prática de seus antepassados, entendem tratar-se de um conhecimento popular que faz parte da história e, portanto, é tratado com respeito e como uma verdade culturalmente reconhecida. Nesse sentido, a ação desenvolvida converge para o que Dickmann e Dickmann (2008, p. 70) assinalam: “o saber popular é entendido como aquele que é fruto das várias experiências vividas e convividas em tempos e espaços diversos na história do povo". Freire (1998) também afirma a importância dos conhecimentos práticos 
adquiridos pela experiência com o ambiente e compartilhados entre as comunidades enquanto meio pedagógico.

Na qualidade de pesquisador facilitador da ação, relatou-se a todas que essa prática antiga se trata de um conhecimento popular sustentado cientificamente, pois a arruda tem compostos flavônicos, cumprindo função analgésica que alivia a dor de cabeça (GRANDI, 2014, p. 141).

Dona E. questionou certas propriedades do chá de arruda referentes ao aparelho reprodutivo feminino, facilitando a liberação da menstruação, num momento em que estava em dúvida se estava grávida. Nesse momento se faz a práxis do pesquisador participante, que traz o conhecimento científico como facilitador do diálogo e, nesse caso, vem dar veracidade ao conhecimento popular difundido no grupo. Explicou-se que a arruda tem uma substância chamada de undecanona, que deve ser evitada por mulheres no início da gestação, pois causa a contração dos músculos do útero e provoca forte hemorragia, podendo levar ao aborto (RIBEIRO, 2014, p. 45).

$\mathrm{Na}$ terceira e quarta semanas de outubro, já mais à vontade com as ervas medicinais e os procedimentos, as participante sescolheram as ervas para a oficina de produção de sabonetes artesanais. Foram selecionados o alecrim, a calêndula e a rosa mosqueta. Após essa escolha, iniciou-se o diálogo sobre os benefícios dessas ervas no uso tópico, evidenciando uma troca de saberes. É importante destacar que a dialogicidade é uma estratégia fundamental da pesquisa para refletir sobre os conhecimentos, conforme nos aponta Freire (1985, p. 45), sendo a "pergunta" uma forma específica e ativa de participar do processo de aprendizagem. Falou-se sobre a atividade proposta e elas, na sequência, relataram sobre suas experiências, como mostra, por exemplo, o diálogo a seguir:

- Dona M. (58 anos): Mas alecrim eu uso como tempero! Pode ser usado como chá também?

Respondeu-se que sim; o alecrim é uma erva que tem um grande leque de possibilidades de uso: como tempero, para carne ou feijão; ou como um chá para ativar a memória; ou ainda como sabonete para inibir oleosidade da pele. 
Pressupõe-se que as escolhas das três primeiras ervas se deveu à curiosidade e, também, ao estranhamento das mulheres acerca de outras formas de uso do alecrim para além do tempero, ou seja, como benefício medicinal através do chá ou na forma de sabonete para tratar a pele. Nessa tarde foram produzidos sabonetes de ervas medicinais considerando que as ervas podem ter diferentes funções, tanto no uso como chá (interno) quanto no uso como sabonete (externo e tópico), a partir do conhecimento prévio da pesquisadora.

Terminou-se de registrar os conhecimentos populares que o grupo revelava sobre as ervas com a dinâmica "Você sabia?" com a arruda e o alecrim, conforme se apresenta na Figura 4, acrescentando informações sobre as demais propostas no início da ação (erva cidreira, camomila e hortelã).

Figura 4 - Dinâmica Você sabia?

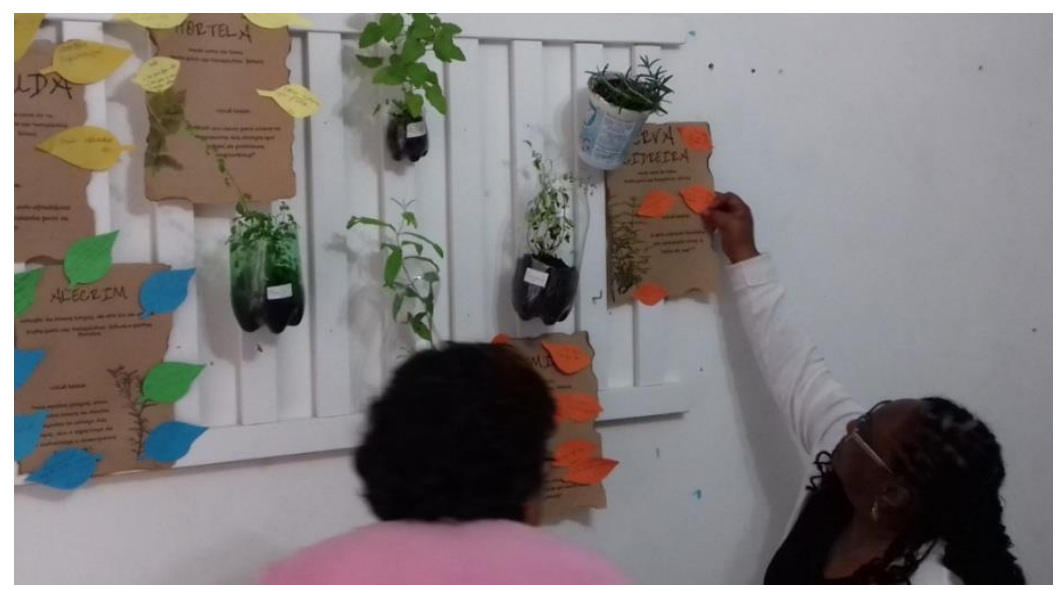

Fonte: Arquivo pessoal, 2017

Essa atividade ressaltou a participação de todas e valorizou os seus saberes sobre as ervas para além de seu uso como chás medicinais, pois, às vezes, as ervas são tratadas como condimentos ou para tratar aspectos espirituais, como banho de descarrego, por exemplo. Isso mostra que o seu uso está intrínseco na cultura e na história da comunidade quilombola. 


\section{Dos diálogos informais surgem as falas significativas}

A Educação Popular, como salienta Brandão (1984, p. 72), "realiza-se em todas as situações em que as pessoas trocam experiências, recebem informações, criticam ações e situações", aprendendo por meio da reflexão sobre suas práticas e vivências. É a partir dos saberes e experiências compartilhados que o saber popular vai sendo transmitido, de geração em geração, sendo transformado e adquirindo novos significados.

Na última semana de outubro, após a realização das oficinas de sabonetes, foi realizado um intervalo para um lanche coletivo, momento adequado para o surgimento de uma série de conversas informais com todas as mulheres sobre diversos assuntos, além das ervas e sabonetes. Esse momento foi criado para que a conversa se desse de maneira "solta", a fim de compreender nestes diálogos como os saberes populares são passados de geração em geração. Nessa tarde, durante a prática das oficinas de ervas e de sabonetes, uma mulher mais jovem da comunidade, que não participava da atividade, entrou na sala e se dirigiu a Dona S. (71 anos) perguntando:

- Mulher: Dona S., a senhora tem ainda aquele chá que a senhora faz para a gripe? Meu marido amanheceu meio ruim com dor de garganta e ele tem que ir trabalhar.

- D. S.: Não tenho, acabou, mas vou fazer mais tarde.

O chá é bem conhecido pela comunidade e é produzido pela Dona S. em sua casa; é distribuído aos poucos para quem precisa, e que vai até ela buscar ajuda no trato de enfermidades rotineiras.

Esse relato é importante para a pesquisa, pois evidencia que as mulheres mais velhas da comunidade detêm o conhecimento do uso das ervas e que mantêm uma relação com a natureza. Conforme Leff (2009, p. 19), esses saberes e essa valorização do meio natural, transmitidos entre gerações e culturas por meio do diálogo, precisam ser reafirmados, pois são essenciais para sustentabilidade da vida (e da humanidade).

Perguntou-se de que chá se tratava e se ela poderia contar quais ervas usava no preparo. Nesse momento, todas as demais riram e informaram: "Ela não conta! É um segredo de família". No entanto, ela informou que diria em outro momento. Observa-se 
aqui a relação de status na comunidade de quem detêm o conhecimento das ervas e faz a transmissão desse conhecimento através das práticas cotidianas como um chá para gripe. Entende-se que o saber sobre as ervas medicinais tem importância para as mulheres quilombolas, que fazem uso e compartilham esses saberes com a comunidade mesmo que de forma hierárquica.

\section{Oficina de sabonetes: liberdade de criação}

No último mês de ação, nas primeiras semanas, foram exercitadas as manualidades, ou seja, as atividades realizadas manualmente, de forma artesanal, como mostra a Figura 5. Essa experiência buscou valorizar o conhecimento das mulheres sobre as ervas medicinais, através da produção de sabonetes artesanais.

Figura 5- Produção sabonetes artesanais com ervas medicinais

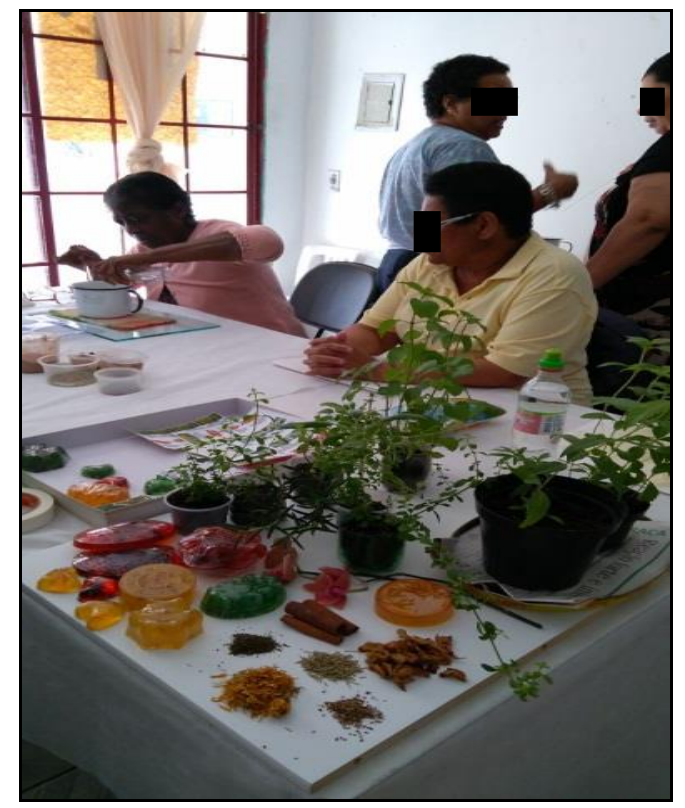

Fonte: Arquivo pessoal, 2017

O processo de aprendizagem, a partir de conhecimentos pré-existentes, aponta para um "poder fazer", traduzido na ideia de empoderamento. A participação de todas as envolvidas na produção dos sabonetes caracteriza-se como emancipatória, pois promove autonomia do grupo e pode ser entendida como "ser ou fazer parte" do processo de empoderar-se (TASSARA; TASSARA; ARDANS, 2014, p. 158). 
Para as mulheres do grupo parecia que criar representou uma intensificação, um vivenciar-se no fazer. Não substituía a realidade, era a realidade. Contudo, era uma realidade nova que adquiria dimensões novas, pelo fato de estarem articulando em si e perante si mesmas, em níveis de consciência mais elevados e mais complexos (OSTROWER, 2001). Foram afetos e memórias, diferentes contextos e perspectivas, que constituíram esse ambiente como um espaço educativo, de educação popular e de liberdade de criação, considerando que:

Mais fundamental e gratificante, sobretudo para o indivíduo que está criando, é o sentimento concomitante de reestruturação, de enriquecimento da própria produtividade, de maior amplitude do ser, que se libera no ato de criar. (OSTROWER, 2001, p.28)

Olhando-as de maneira sensível, os olhos expressivos e o próprio produto resultante do criar, a realidade manifestada, inventada e representada no objeto, era possível compreender a ocorrência de inúmeras aprendizagens. Estas, por sua vez, incluíam um sentimento de poder mudar e criar, de se mostrar no objeto inventado, de se representar e representar sua realidade. Foi a partir desse sentimento que percebi um crescimento interior que contribuiu para os processos emancipatórios das mulheres do grupo, que se viam capazes de criar, inventar novas possibilidades, revelar-se e expressar seus sentimentos e de se empoderarem para a vida (Figuras 6 e 7).

Figuras 6 e 7 - A criatividade expressa em sabonetes

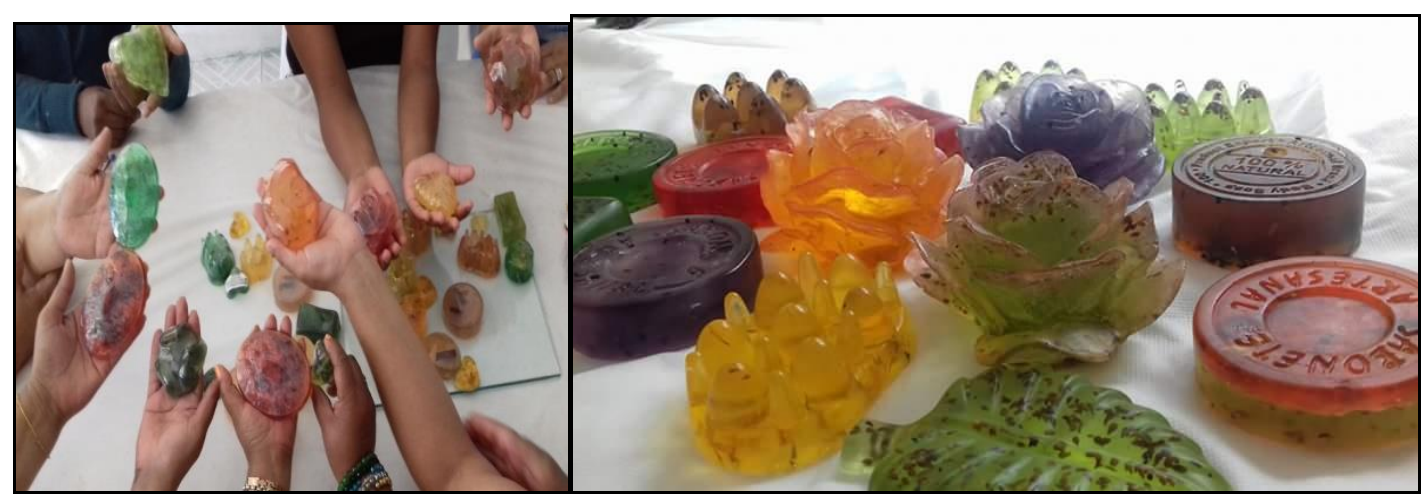

Fonte: Arquivo pessoal, 2017 
Na terceira semana, percebeu-se que os encontros realizados sempre mantinham a dialogicidade num espaço em que elas pudessem se sentir ensinantes e aprendentes, em que o diálogo fosse entendido como algo da própria natureza humana (FREIRE,1980, p. 122). Nos encontros, o saber de todas pode ser falado, ouvido e valorizado, num entendimento de que dialogar garante e estimula a fala do outro. Dialogar não é apenas trocar ideias por meio de palavras ocas, é também se enxergar na fala do outro: “...o verdadeiro diálogo não pode existir se os que dialogam não se comprometem com o pensamento crítico..." (FREIRE, 1980; p. 83-85). O diálogo consiste numa relação horizontal e não vertical entre as pessoas implicadas e entre as pessoas em relação. No seu pensamento, a relação homem/mulher/mundo é indissociável. O diálogo produz a conscientização libertadora e transformadora, ou seja, dialógica:

O diálogo é este encontro dos homens, mediatizados pelo mundo, para pronunciá-lo, não se esgotando, portanto, na relação eu-tu. Esta é a razão por que não é possível o diálogo entre os que querem a pronúncia do mundo e os que não querem; entre os que negam aos demais o direito de dizer a palavra e os que se acham negados deste direito. (FREIRE, 2005, p. 91)

Ao mesmo tempo, a experiência com essas mulheres revela suas reações à negação a que se veem confrontadas cotidianamente em relação ao seu conhecimento tradicional pelo mundo exterior. Destacam-se aqui três reações verificadas nas oficinas. A primeira é o uso da pergunta e do questionamento como instrumento de reafirmação de seus próprios conhecimentos. Ao perguntarem, apesar de saberem de antemão a resposta, elas iniciam o diálogo buscando se assegurar se o que tinham para dizer tem validade. Ao final da resposta, sempre havia uma complementação, demonstrando que o conhecimento existe e pode até ir além do que foi tratado no diálogo. Assim, se confirma a importância da Pedagogia da Pergunta discutida por Freire (1985).

A segunda reação é a expressão do conhecimento de forma velada ou indireta. Os conhecimentos não são explicitados claramente, mas aparecem de forma quase despropositada. Foi o caso de Dona S., ao deixar displicentemente sobre a mesa em que 
trabalhava uma "receita" do que chamou de "banho de ervas para descarrego", para que fosse vista e remetesse a uma pergunta sobre do que se tratava, como mostram as Figuras 8 e 9. Ela então, respondendo, leu a receita para todo o grupo em voz alta.

Figura 8 e 9 - Receita de Dona S. para “descarrego"

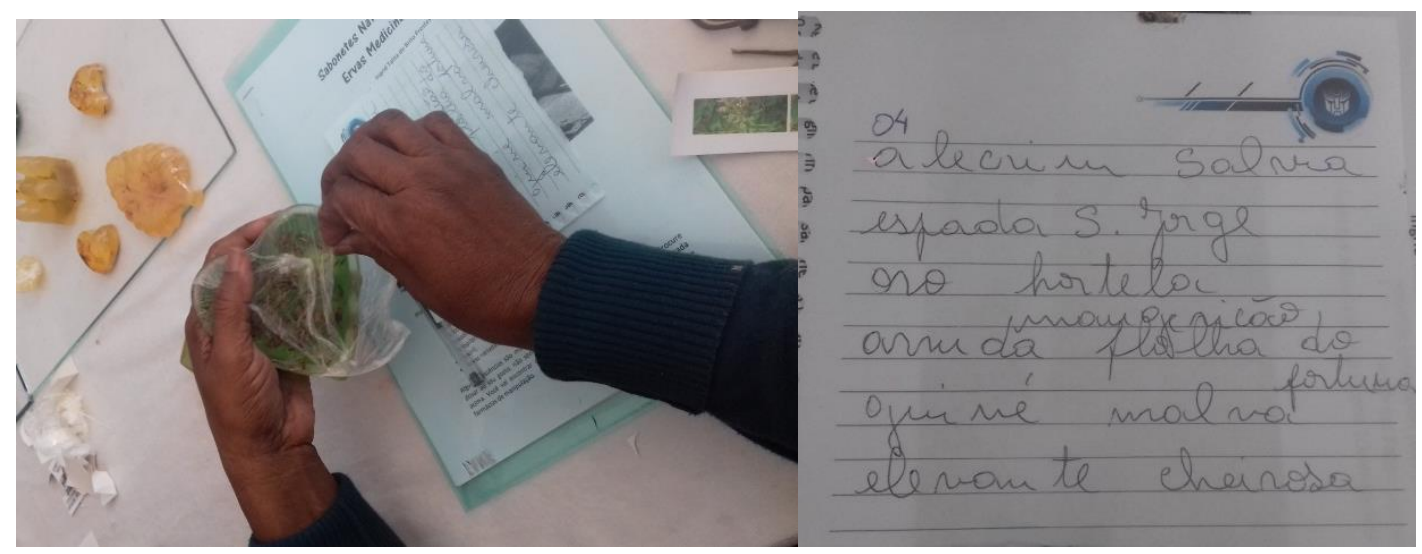

Fonte: Arquivo pessoal, 2017

Esse episódio permitiu que elas, logo em seguida, escolhessem trabalhar com as sete ervas que estão associadas ao "descarrego". Essa demonstração de interesse pelas experiências entre as mulheres pode ser interpretada com uma forma de valorização ou reconhecimento de sua cultura, ainda que tímida e embrionariamente exposta. Dona S. demonstra ser a mulher que mais possui conhecimento sobre ervas, ao falar num dos encontros que precisaria sair mais cedo para fazer uma simpatia.

\section{"O relógio do corpo humano"}

Para a última semana da ação foi reservado um diálogo entre saberes populares e científicos. Entendendo que o grupo funciona melhor com dinâmicas lúdicas, utilizou-se um jogo para que fossem discutidos os melhores horários para tomar os chás de ervas medicinais. Este jogo consiste em um tabuleiro com um relógio, que apresenta os horários mais adequados para tratamento de diferentes órgãos do corpo humano com o uso de ervas medicinais (Figura 10). Todas as participantes estavam munidas de fichas, cada uma contendo o nome do chá e para que é indicado. Começou-se o jogo com a

\footnotetext{
${ }^{6}$ Descarrego é como se chama popularmente uma atividade que busca retirar as más energias dos indivíduos, através de banho com ervas específicas.
} 
primeira participante sugerindo um problema de saúde (exemplo: dor de estômago) e quem estivesse com a ficha do chá indicado para tratar o estômago deveria procurar no relógio o horário certo para tomar o chá e colocar a ficha no tabuleiro, sugerindo, em seguida, um próximo problema de saúde para realizar a mesma dinâmica. O jogo chegou ao seu final quando todas as fichas foram colocadas no tabuleiro, completando o relógio do corpo humano.

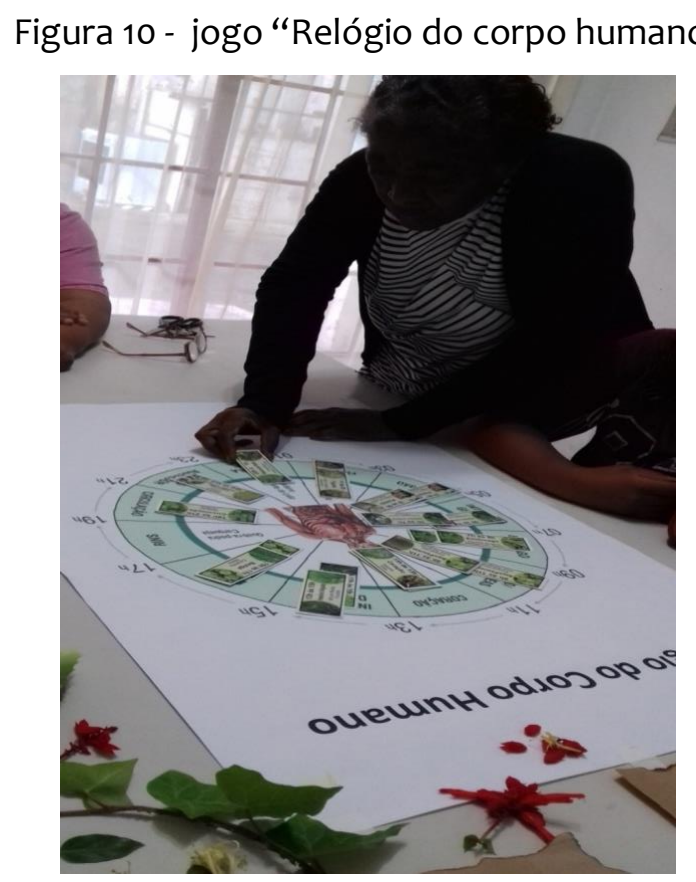

Fonte: Arquivo pessoal, 2017

O jogo do relógio do corpo humano reuniu saberes científicos e populares oferecidos no diálogo entre as mulheres durante toda a atividade, que por vezes sugeriram outros chás que não estavam nas fichas, mostrando seu conhecimento para além do que já havia sido trazido. Essa experiência nos remete a Freire (1998; p. 24-25), para quem "ensinar não é transferir conhecimento, mas criar as possibilidades para a sua produção ou a sua construção". As mulheres da comunidade também denominavam os chás que estavam nas cartelas com outros nomes. 


\section{Considerações finais}

A ação realizada no Quilombo com as oficinas de chás e sabonetes de ervas medicinais, foi rica em aprendizagens. Em certa medida, porque se desenvolveu em um espaço educativo não escolar, o que permitiu novas formas de expressar o conhecimento. O conhecimento tradicional que circula na comunidade diz respeito às informações acumuladas ao longo do tempo, por suas práticas, seus valores, suas crenças, sua cultura, seus saberes populares, suas vivências e experiências. Tais conhecimentos são modificados e reformulados pela comunidade ao longo da história.

As vivências no quilombo conduzem à reflexão de que "a educação ambiental é o processo dialógico que fertiliza o real e abre a possibilidade para que se chegue a ser ainda o que não se é" (LEFF, 2009, p. 23). Contudo, acredita-se ser na partilha da lembrança dos saberes populares sobre as ervas, que aquelas mulheres têm guardados em suas memórias e vivências, que se evidenciou o entendimento da valorização do saber popular de sua transmissão de geração em geração, de sujeito a sujeito, caracterizando-o como um bem ambiental e cultural.

No entanto, a participação de todos os envolvidos como agentes de todo o processo pode se caracterizar como emancipatória, pois promove autonomia de decisão, que significa emancipação e, consequentemente, pode ser entendida como "ser ou fazer parte" (TASSARA; TASSARA; ARDANS, 2014, p. 158). Assim, o educando participante se emancipa. Em síntese, a EA popular pode promover processos emancipatórios e pode levar os sujeitos a se empoderarem.

É preciso mencionar o quão importante foi perceber que a ação de EA privilegiou o diálogo de saberes sobre as ervas, suas significações e representações, legitimando os saberes populares dessas mulheres. Destaca-se também que, ao fim da ação, superou-se o problema inicial: a identificação da fragilidade do reconhecimento pelas mulheres quilombolas da importância de seus saberes populares e da relação destes com o meio ambiente, para o fortalecimento da sua realidade socioambiental. Nesse sentido, entende-se que essa ação de EA junto a essa comunidade foi importante para, entre 
outros aspectos, estimular a autovalorização das suas práticas culturais, como parte fundamental na consolidação da vida social da comunidade quilombola.

\section{Referências}

BRANDÃO, Carlos Rodrigues. Repensando a pesquisa participante. São Paulo: Brasiliense, 1984.

BRANDÃO, Carlos Rodrigues. A pergunta a várias mãos: a experiência da pesquisa no trabalho do educador. São Paulo: Cortez, 2003.

DICKMANN, Ivo; DICKMANN, Ivânio. Primeiras palavras em Paulo Freire. Passo Fundo: Battistel, 2008.

FIGUEIREDO, Nébia Maria Almeida. Método e metodologia na pesquisa científica. 2. ed. São Caetano do Sul, São Paulo, Yendis Editora, 2007.

FREIRE, Paulo. Conscientização. Teoria e prática da libertação. Uma introdução ao pensamento de Paulo Freire. Tradução de Kátia de Mello e Silva; revisão técnica de Benedito Eliseu Leite Cintra. São Paulo: Cortez e Moraes, 1980.

FREIRE, Paulo. Por uma pedagogia da pergunta. Rio de Janeiro: Paz e Terra, 1985.

FREIRE, Paulo. Pedagogia da autonomia: saberes necessários à prática educativa. 8. ed. Rio de Janeiro: Paz e Terra. 1998; p. 25.

FREIRE, Paulo. Pedagogia do oprimido. 42. ed. Rio de Janeiro: Paz e terra, 2005.

GRANDI, Telma Sueli Mesquita. Tratado das plantas medicinais: mineiras, nativas e cultivadas. Belo Horizonte: Adaequatio Estúdio, 2014.

HOROCHOVSKI, Rodrigo Rossi; MEIRELLES, Giselle. Problematizando o Conceito de Empoderamento. SEMINÁRIO NACIONAL MOVIMENTOS SOCIAIS, PARTICIPAÇÃO E DEMOCRACIA, 3. Anais... Florianópolis: UFSC, 2007.

LEFF, Enrique. Complexidades, Racionalidade Ambiental e Diálogos de Saberes. Educação \& Realidade, Porto Alegre. v.34, n. 3, set/dez.2009. p.17-24.

LAYRARGUES, Philippe Pomier. Para onde vai a Educação Ambiental? O cenário Políticoideológico da Educação Ambiental Brasileira e os desafios de uma agenda Política Crítica 
Contra Hegemônica. Revista Contemporânea de Educação, n. 14, ago./dez. de 2012. p. 398-421.

LÜDKE, Menga; ANDRÉ, Marli. Métodos de coleta de dados: observação, entrevista e análise documental. In: LÜDKE, M.; ANDRÉ, M. E. D. A. Pesquisa em educação: abordagens qualitativas. São Paulo: EPU, 1986, p. 25-44.

O'DWYER, Eliane Cantarino. Os quilombos e as fronteiras da antropologia. Antropolítica: Revista Contemporânea de Antropologia e Ciência, Niterói, n. 19, 2. sem. 2005. p. 91-111.

OSTROWER, Fayga. Criatividade e processos de criação. Petrópolis: Vozes, 2001.

PINHEIRO, Paulo César; GIORDAN, Marcelo. O preparo de sabão de cinzas em Minas Gerais, Brasil: do status de etnociência à sua mediação para a sala de aula utilizando um sistema hipermídia etnográfico. Investigações em Ensino de Ciências, Porto Alegre, v. 15, $\mathrm{n}^{\circ} .2$, p. 355-383, agosto, 2010.

REIGOTA, Marcos. O que é educação ambiental. São Paulo: Brasiliense, 2001.

RIBEIRO, Camila dos Santos Padovani. Determinação espectrofotométrica de flavonoides totais presentes nas folhas de arruda (Ruta Graveolens L). 2014. Trabalho de Conclusão de Curso - Fundação Educacional do Município de Assis (FEMA), Assis, 2014.

SORRENTINO, Marcos. Educador Ambiental Popular. In: ENCONTROS E CAMINHOS: formação de educadoras(es) ambientais e coletivos e coletivos educadores. v. 3. Brasília: MMA/DEA, 2014. p. 141-153.

TASSARA, Eda Terezinha de Oliveira; TASSARA, Helena; ARDANS, HectorOmar. Empoderamento (versus Empoderar-se). In: ENCONTROS E CAMINHOS: formação de educadoras(es) ambientais e coletivos educadores, v. 3. Brasília: MMA/DEA, 2014, p. 155163. 